\title{
Patient Blood Management Implementation Strategies and Their Effect on Physicians' Risk Perception, Clinical Knowledge and Perioperative Practice - the Frankfurt Experience
}

\author{
Dania P. Fischer ${ }^{a} \quad K a i$ D. Zacharowski ${ }^{a}$ Markus M. Müller ${ }^{b} \quad$ Christof Geisen $^{b}$ \\ Erhard Seifried $^{\mathrm{b}}$ Heiko Müller ${ }^{\mathrm{a}}$ Patrick Meybohm ${ }^{\mathrm{a}}$ \\ a Department of Anesthesiology, Intensive Care Medicine and Pain Therapy, University Hospital Frankfurt, Frankfurt/M., Germany; \\ ${ }^{b}$ German Red Cross Blood Transfusion Service Baden-Wuerttemberg - Hessen, Institute of Transfusion Medicine and \\ Immunohematology, Frankfurt/M., Germany
}

\section{Keywords}

Patient blood management · Anemia - Blood transfusion . Surgery - preoperative period - Medical decision-making . Implementation strategy

\section{Summary}

Introduction: A multicomponent, evidence-based and interdisciplinary Patient Blood Management (PBM) program was introduced at the University Hospital Frankfurt in July 2013. The implementation strategy included practical and tactical components aimed to increase knowledge on the risks of preoperative anemia, to standardize hemotherapy, and to facilitate PBM components. Methods: This article analyzes barriers to PBM implementation and outlines a strategy to introduce and manifest PBM. The effects in Frankfurt were measured in a before and after questionnaire study distributed among groups of physicians immediately before and 1 year after PBM implementation. Results: 142 clinicians completed the questionnaire in July 2013 and 101 clinicians in August 2014. Absolute certainty that the treatment of preoperative anemia favorably influences morbidity and mortality rose from 25 to $37 \%$. Transfusion behavior seems to have been affected: In 2014, 56\% of clinicians stated that they clinically reassess the patient and analyze hemoglobin following each single red blood cell unit compared to only $38 \%$ stating this in 2013 . Conclusion: These results show that our implementation strategy was effective in changing physicians' risk perception, attitude, and knowledge on PBM principles. Our experience highlights key success factors for the implementation of a comprehensive PBM program.

\section{Introduction}

Patient Blood Management (PBM) is an evidence-based, multidisciplinary approach to optimize the care particularly of those patients who are at risk of anemia and/or might need blood transfusions during hospitalization. PBM encompasses the pre-interventional optimization of red blood cell ( $\mathrm{RBC}$ ) mass, the minimization of blood loss, and the advancement of appropriate transfusion decision making. The imperative goal is to improve clinical outcome and patient safety.

The medical background of PBM is based on two major points: Firstly, anemia is associated with worse postoperative outcome, higher rates of infectious complications, prolonged hospitalization, and an increased likelihood of allogeneic blood transfusions [1-4]. Secondly, increasing evidence suggests that over-transfusion of allogeneic blood products is associated with increased morbidity and mortality due to infectious, immunological, pulmonary, and thromboembolic complications [5-8]. Especially worrisome is the substantial inter-institutional variability of transfusion practice, implicating high levels of insecurity regarding the indication for hemotherapy and potentially inappropriate usage $[9,10]$. Furthermore, it appears odd that hemoglobin levels of critically ill patients on intensive care units show a convergence over time, irrespective of the admitting hemoglobin level, age, and comorbidities [11]. PBM programs tackle these problems, using a multidisciplinary, multimodal, patient-focused approach to screen for, avoid and treat anemia as well as to minimize and standardize RBC transfusion with the ultimate goal of improving patient outcome [12, 13].

The World Health Organization (WHO) has been officially urging member states to implement PBM since 2010 (WHA63.12). PBM programs have already been rolled out more or less success-

\section{KARGER \\ Fax +497614520714

\section{(c) 2015 S. Karger GmbH, Freiburg}

$1660-3796 / 15 / 0422-0091 \$ 39.50 / 0$
Dr. Dania Fischer

Department of Anesthesiology, Intensive Care Medicine and Pain Therapy University Hospital Frankfurt

Theodor-Stern-Kai 7, 60590 Frankfurt, Germany

dania.fischer@kgu.de 


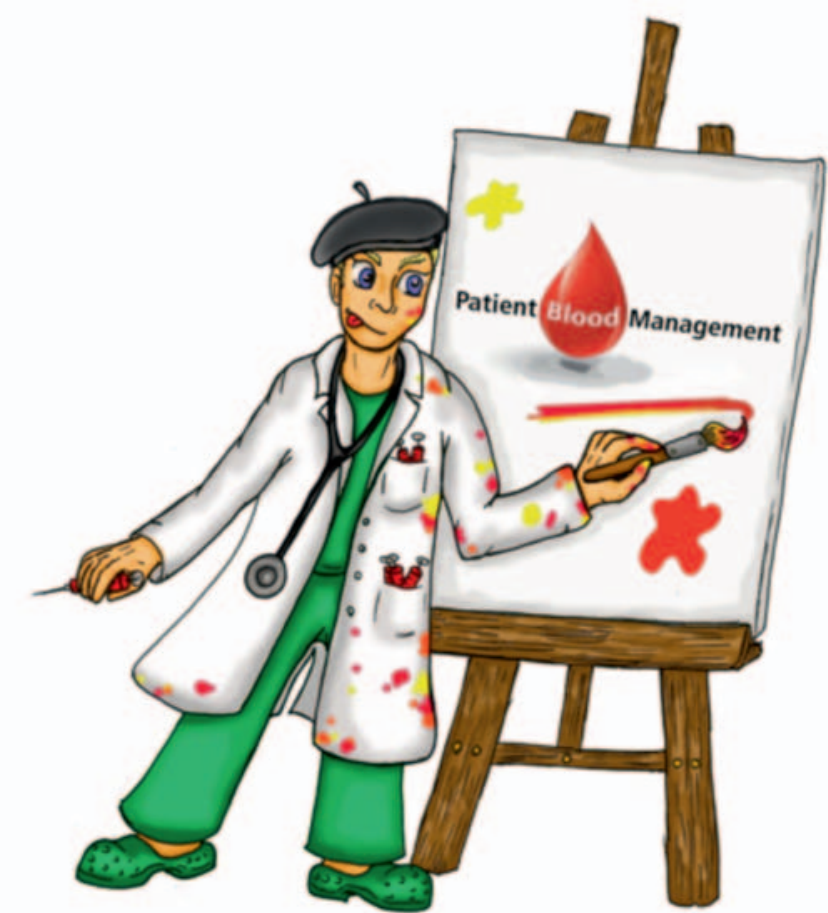

Fig. 1. Art versus science? A physician's craftsmanship applied to the field of science. - by Dr. Pia Ockelmann.

fully in most of Western Australia centers and in a few centers in Europe and the USA [14-16]. Hence, there are vast regions around the world where PBM concepts still await profound and sustainable implementation. Acknowledging this, the European Commission recently announced a pilot program for the implementation of PBM in five European teaching hospitals [17]. It has to be emphasized that the implementation of PBM is of critical importance especially in Germany as it has one of the highest blood usages worldwide: 51.1 RBC units per 1,000 population (2013) are transfused [16] as compared to 27.5 units per 1,000 in Western Australia (2012) [18].

However, experience from guideline implementation in other medical fields shows that this can be a very challenging task: despite a wide promulgation of evidence-based practice, adherence is often poor and the implementation into daily routine may take decades $[19,20]$. Thus, in order to implement new standards of care successfully, it seems reasonable and necessary to analyze the formation of medical decisions alongside the pragmatic, educational, and attitudinal obstacles to evidence-based practice. This article outlines methods to influence the behavior of medical care providers and suggests an action plan for the wider implementation of PBM programs.

The recommendations are based on experience from launching a multicenter PBM program in four German university hospitals, affecting the care of more than 50,000 surgical patients/year. As sustainable behavioral changes can only result from influencing knowledge and attitude; both are targeted by the measures proposed [21].

\section{Medical Decision Making and Motivation}

Many guidelines, based on excellent trials, are available that are not being followed due to various barriers preventing their application [19]. The barriers impeding the employment of evidencebased practice are manifold: One main point is paucity of knowledge as keeping up to date with evidence-based data is time-consuming. As regards PBM and transfusion practice, these important subjects are to date underrepresented in the education of young physicians. The resulting significant variation in hemotherapy and patient care is often based on inadequate interpretation of controversial evidence, errors in reasoning, gross oversimplification and wide variations in belief [22]. Furthermore, lack of agreement, of self-efficacy in light of the overwhelming volume of clinical responsibilities and of outcome expectancy as well as inertia of previous practice aggravate this problem. A widespread apprehension of excessive clinical guideline proliferation is also a potential barrier in terms of physician attitude [21]. Personal reservations concerning any external influences on practice patterns are met with skepticism that autonomy will be eroded and practice will become more protocol driven [23].

From our point of view, the key to a successful initiation and maintenance of a large-scale behavioral change is the understanding what motivates medical professionals. We believe that health care providers are generally motivated to make right decisions. However, it is important to consider that transfusion decisions are highly complex and affected by many factors, ranging from a sincere but often unsubstantiated desire to maintain health and ensure and accelerate patients' recovery to an arbitrary phobia of any legal consequences. Therefore, recommendations and standard operating procedures need to be easily accessible, science-based, and aimed at supporting clinical judgment as the cornerstone of patient care. Smooth infrastructure should be provided to overcome practical barriers, and regular evaluation of effects on outcome should function as an iterative feedback for medical professionals. When designing the desired change, it is very important to communicate that medicine is not just science applied to products, but an art of combining evidence and experiences in new and diverse situations to the best solution for each individual patient. It should be kept in mind that even if guidelines offer evidence-based information, their scope is still limited to the realm of the 'knowledge' in medicine. For them to additionally address the 'art' element in medicine effectively, multifaceted tools have to be applied to alter transfusion behavior [24]. Figure 1 illustrates a medical artist, applying a physician's craftsmanship to the field of science - resulting in a PBM logo symbolic for prosperous interlocking and better patient care.

\section{Patient Blood Management}

\section{Developing a PBM Concept That Fits into Your Health Care Facility}

Many important factors such as infrastructure, staff, equipment, and economic resources differ between hospitals, and individuali- 
Table 1. Key strategies to implement PBM programs [35]

\begin{tabular}{|c|c|}
\hline Target & Method \\
\hline Knowledge & $\begin{array}{l}\text { - Develop clinical education materials for M.D.s that include the risks and benefits of anemia and transfusion. } \\
\text { Convey the best practices and guidelines supported by evidence. Expand education on transfusion avoidance } \\
\text { and appropriate alternatives to transfusion } \\
\text { - } \quad \text { Distribute educational materials via website and/or central virtual room and prepare comprehensible checklists } \\
\text { - } \text { Appoint local guideline implementation teams to teach and maintain the program's components } \\
\text { - } \quad \text { Design optional examination course with an associated certificate on transfusion practice and PBM } \\
\text { - } \quad \text { Standardize performance metrics and data collection to allow valid benchmarking within organizations. } \\
\text { Identify research priorities to close evidence gaps in what constitutes optimal transfusion practice } \\
\text { - } \quad \text { Develop a separate informed consent process consistent with current evidence for transfusion that } \\
\text { - communicates the risks and benefits } \\
\text { Coordinate regular exposure to PBM during medical school, continuing professional education, residency } \\
\text { - curriculum } \\
\text { - Offer hands-on workshops with simulated patient contacts in the perioperative setting } \\
\text { - Identify elective procedures where patients will benefit from early anemia screening and therapy }\end{array}$ \\
\hline Attitude & $\begin{array}{l}\text { - Foster team spirit and corporate identity } \\
\text { - Vocabulary: develop a concept that fits into your hospital } \\
\text { - Communicate the flexibility of measures and be open-minded to input from all parties involved } \\
\text { - Highlight learning-continuum for all } \\
\text { - Aggressive marketing: i.e. logo, poster, flyer, promotion booth, PBM-T-Shirts for Charity-runs, } \\
\text { car advertising, buttons, ties, shirts, pens, PBM-hotline } \\
\text { - Identify subject matter experts - local opinion leaders within organizations to provide guidance } \\
\text { - Invite journalists from medical and general papers and television delegates who support the propagation } \\
\text { of the PBM idea } \\
\text { - Hire PBM 'ambassador' as a incarnated reminder }\end{array}$ \\
\hline Behavior & $\begin{array}{l}\text { - Change the infrastructure and preoperative flow of patients - } \\
\text { - Decrease preclinical pressure by allocating greater time frames ahead of elective surgery } \\
\text { - Define and allocate clear responsibilities for the investigation and treatment of anemia (preoperative } \\
\text { assessment) } \\
\text { - } \quad \text { Provide low-threshold logistics by improving computer information support services } \\
\text { - Advocate scheduled periodic assessments of physicians' PBM competency and for accountability to } \\
\text { organizational standards as part of ongoing professional practice evaluation } \\
\text { - Measure individual physician transfusion practice via hard facts such as RBC units transfused, } \\
\text { - } \text { patients screened for anemia etc. } \\
\text { - } \quad \text { Include guidelines into Standard operating procedures (make treatment algorithms available online) } \\
\text { - Create visual aids - check-lists for the walk-in-clinic and operation rooms }\end{array}$ \\
\hline
\end{tabular}

zation is vitally important for the social acceptance of any new standard [25]. For this reason, PBM programs need to be specifically designed for each site using the bigger frame of the recommended PBM concept. A multidisciplinary agenda can maximize its acceptance. The Frankfurt University Hospital PBM program, for instance, was based on a consensus between a large team of medical professionals, including hematologists, surgeons, gastroenterologists, anesthesiologists, critical care physicians, laboratory technicians as well as administrative and quality management personnel. The most important partner in the development and implementation of the PBM scheme is The German Red Cross Blood Donor Service Baden-Wuerttemberg - Hessen as the provider of all blood products used at the University Hospital Frankfurt.

An official order from the University Hospital Board chaperones the program, adding authority. For organizational reasons, PBM in Frankfurt initially focused on surgical patients; however, the non-surgical setting is just as important and should be included to achieve maximum benefit for the patients.
Besides being multidisciplinary in origin, new standards need to be practical and feasible. This is why we think that it is important to communicate throughout the implementation period that the project is alive and flexible. Constructive criticism and suggestions from the whole medical community are highly important to adjust and improve the program and should be welcomed. Hospitals with similar settings should collaborate and create or participate in joint PBM programs.

\section{Systematic Methods for Designed Behavior Change}

Before practice guidelines can positively affect patient outcome, they first need to affect physicians' knowledge, attitude, and finally behavior [21]. During the implementation phase, multiple training programs were undertaken in the four German University Hospitals in order to increase knowledge on the risks of preoperative anemia and the indications of blood transfusions, and to facilitate the execution of PBM components. In order to monitor the induced changes in risk perception, clinical knowledge and periop- 
erative practice, we used a questionnaire study at the University Hospital Frankfurt before and 1 year after the introduction of PBM. Physicians were asked about their exposure to PBM recommendations and their knowledge of the components of the multifaceted intervention. Furthermore, their individual desire to change practice was assessed. This questionnaire was a first incentive for people to reflect their transfusion behavior.

\section{Learning and Closing Knowledge Gaps}

There are a number of ways in which individuals learn new information, and these should be addressed effectively. The PBM learning materials need to be related to physician goals. Essentially, this can be achieved by stressing the clinical implications of anemia and the need for alternatives to transfusion. The focus should be placed upon clinical outcomes and the inappropriateness of transfusion practice variability. The learning materials should be easily accessible, e.g. via a website (www.patientbloodmanagement.eu) or a central virtual room for documents / guidelines / posters / education materials. In addition, we prepared a local online certification course for PBM and general transfusion practice that can be obtained voluntarily. The systematic strategies applied and recommended by us to influence knowledge, attitude, and behavior are summarized in table 1 .

When scheduling the PBM education program, it is recommended to identify frequent users of blood transfusions to focus on. In this respect, both surgical procedures that are associated with the highest rate of transfused patients and procedures with the highest number of RBC units transfused should be listed. These high-risk surgical procedures should be carefully assessed for their potential to implement further blood-sparing techniques such as cell salvage or topical hemostatic agents. Additionally, this will help identify those elective procedures where patients will benefit from early preoperative anemia screening, diagnosis and therapy, which is crucial for further planning and modification of preoperative patient flows [26].

The local guideline implementation teams performed both group and individual teaching sessions in Frankfurt where they reinforced increasing exposure to and the use of bedside educational materials and checklists. The latter were distributed to all wards and to all operation rooms [28]. For example, the recommendations regarding the screening and therapy of preoperative anemia in Frankfurt were integrated into flow charts and are displayed in the surgical ambulances identifying target patient groups. PBM measures were also incorporated in laboratory order sets. Finally, we recommend hands-on workshops with simulated patient encounters in the perioperative setting as well as coordinated regular exposure to PBM not only during continuing professional education and residency curriculum, but also during medical school. Medical students are the future of health care and should grow up with PBM!

\section{Marketing}

To make sustainable progress in the rationale use of blood, we recommend an aggressive marketing strategy. The Frankfurt PBM working group designed a logo, posters, pens, shirts, and ties to establish a 'brand' and provided flyers to all hospital areas. An advertisement booth was set up in front of the cafeteria, PBM T-shirts were sponsored for a charity-run, and a special PBM hotline was created along with car advertisements. By including the PBM logo on the main homepage of the hospital as a marketing instrument, public attention is directed to the hospital, making it a valuable tool for image promotion. Other ways to propagate the PBM concept are press conferences and meetings with journalists from medical and general papers as well as television delegates. We suggest structural marketing techniques as an important tool for the promotion of the desired paradigm shift in transfusion practice. Lastly, to ensure continuity of the program, we engaged a PBM 'ambassador' as an incarnated reminder and for repetitious 'drill' of PBM contents to ensure coherence and consistency of the program.

\section{Transfer of Learning into Practice}

The establishment of corporate identity boosts desirable behavior as it ignites team spirit, which has a major effect on behavior. The associated social pressure might even foster healthy competition between wards and departments. Appointed PBM experts in every department can lead this movement and establish a social platform online where involved parties can interact and ask each other questions.

The PBM working group should emphasize the importance of having the infrastructure and supportive tools that help physicians making the best decisions and documenting why they were made. Appropriate knowledge and attitude are necessary but not sufficient for adherence; ways have to be paved for a better understanding of coherence. Regarding preoperative diagnostics, the pressure not to delay surgery often hinders an adequate preoperative assessment and improvement of patients. Our recommendation is to relieve pressure by allocating a greater timeframe prior to elective surgery by changing the infrastructure and preoperative flow of patients [27] i.e., provide low-threshold logistics by improving computer information support services and define clear responsibilities for the preoperative diagnosis and treatment of anemia. In Frankfurt, for instance, a noninvasive tool was bought to measure the hemoglobin levels of elective patients via a finger clip device [29]. This also enlivened the professional training through handson practice. It is also advisable to negotiate with health insurance companies for the reimbursement of the measures applied. Finally, it seemed to be helpful to create and hang up visual aids and checklists in the walk-in-clinics and the operating rooms. A continued education program will help to maintain the PBM program and to ensure sustainability.

\section{Measuring the Effects on Patient Outcome}

Other centers and hospitals around the world face similar problems as there is great need for PBM and difficulties in the implementation [30]. Quality assessment of the new standard of care is one way to successfully enhance the acceptance of PBM [31-33]. Periodic assessment of physicians' PBM competency and advocate 
Fig. 2. Comparison of answers to a survey on transfusion policy - 142 participants before PBM (June 2013), 101 after 1 year of PBM (July 2014).

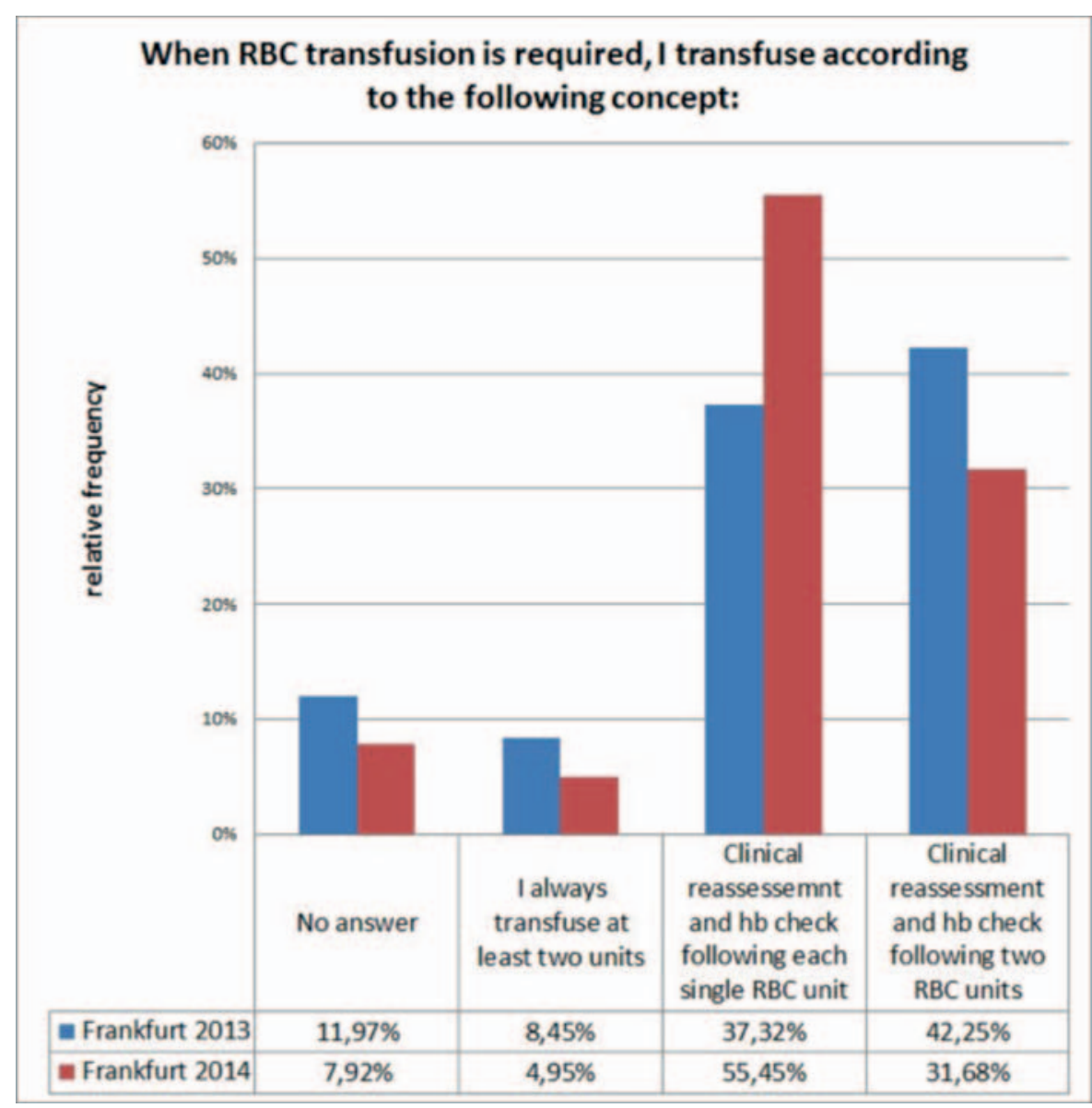

accountability to organizational standards as part of ongoing professional practice evaluation should be scheduled. We are currently conducting a prospective multicenter trial to address safety concerns and to evaluate the cost-effectiveness of our PBM program at four German University Hospitals (Frankfurt, Bonn, Kiel, and Münster). The study will be completed in 2015 (ClinicalTrials.gov Identifier: NCT01820949). A composite endpoint is analyzed including in hospital mortality and morbidity, such as sepsis, myocardial infarction, stroke, renal failure and pneumonia, before and after the implementation of PBM. It is expected that PBM will reduce the incidence of preoperative anemia in elective patients, result in lower blood product usage, and will thereby potentially reduce costs and complications and improve individual patient outcome as it has already been shown in other trials [32, 34]. Such high-quality data will also help to sustain the program through positive feedback to the medical experts.

\section{Results of a Questionnaire Study in Frankfurt}

In order to monitor progress regarding risk perception, clinical knowledge and perioperative practice among the staff, we used a questionnaire at the University Hospital Frankfurt. As PBM in Frankfurt currently focuses on surgical patients and their attending physicians, the questionnaires were distributed to surgeons and anesthesiologists. They were handed out in paper format to physicians attending the introduction session of PBM and before a PBM lecture 1 year thereafter. In July 2013, 142 clinicians completed the questionnaire and 101 in August 2014.

Absolute certainty that the treatment of preoperative anemia favorably influences morbidity and mortality rose from 25 to $37 \%$. Common transfusion triggers changed as well: $29 \%$ compared to $22 \%$ stated that they routinely use 'hemoglobin $<6 \mathrm{~g} / \mathrm{dl}$ ' as an indicator for RBC transfusion. Furthermore, $31 \%$ of the clinicians used physiological transfusion triggers such as ECG changes or lactic acidosis as a trigger for transfusion after 1 year of PBM compared to $27 \%$ before implementation. Additionally, transfusion behavior seems to have been affected as shown in figure 2: After 1 year of PBM, 56\% of clinicians stated that they clinically reassess the patient and analyze hemoglobin following each single RBC unit compared to only $38 \%$ stating this in 2013 . These results show that change is taking place, but there is still potential for future improvement.

\section{Conclusion}

The task of synthesizing up-to-date, evidence-based knowledge and conveying it to clinicians is challenging. The sustainable implementation of new standards of care into daily routine, however, is even daunting. We found that especially the inertia of previous practice often hinders compliance along with skepticism that au- 
tonomy will be eroded by new standards. The obstacles to tackle are paucity of knowledge as well as lack of self-efficacy and outcome expectancy. Furthermore, medicine is not just facts applied to problems, but an art of combining scientific evidence, knowledge, and clinical judgment to the best possible care of our patients! This is important to keep in mind when trying to design a method for change of behavior. Shifting a paradigm takes a long breath, but PBM will make clinicians more knowledgeable and better skilled in caring for their patients and hence result in improved clinical outcomes. Looking down the line, PBM programs will certainly evolve as a main quality indicator for hospitals.

Additionally, our results show that our implementation strategy was effective in changing physicians' risk perception, attitude, and knowledge on PBM principles, and our experience highlights key success factors for the implementation of a comprehensive PBM program.

\section{Acknowledgments}

We thank our colleague Dr. Pia Ockelmann for drafting figure 1.

\section{Disclosure Statement}

The implementation of Frankfurt's Patient Blood Management Program in four German university hospitals is supported by Vifor Pharma, B. Braun Melsungen AG, CSL Behring, Fresenius Kabi.

Prof. Zacharowski's department is receiving unrestricted educational grants from B. Braun Melsungen AG, Fresenius Kabi GmbH, CSL Behring GmbH and Vifor Pharma GmbH.

In the past 3 years, Prof. Zacharowski has received honoraria or travel support for consulting or lecturing from the following companies: Abbott $\mathrm{GmbH} \&$ Co KG, Aesculap Akademie GmbH, AQAI GmbH, Astellas Pharma GmbH, Astra Zeneca GmbH, Aventis Pharma GmbH, B. Braun Melsungen AG, Baxter Deutschland GmbH, Biosyn GmbH, Biotest AG, Bristol-Myers Squibb GmbH, CSL Behring GmbH, Dr. F. Köhler Chemie GmbH, Dräger Medical GmbH, Essex Pharma GmbH, Fresenius Kabi GmbH, Fresenius Medical Care, Gambro Hospal GmbH, Gilead, GlaxoSmithKline GmbH, Grünenthal GmbH, Hamilton Medical AG, HCCM Consulting GmbH, Heinen+Löwenstein GmbH, JanssenCilag GmbH, med Update GmbH, Medivance EU B.V., MSD Sharp \& Dohme GmbH, Novartis Pharma GmbH, Novo Nordisk Pharma GmbH, P. J. Dahlhausen \& Co. GmbH, Pfizer Pharma GmbH, Pulsion Medical Systems S.E., Siemens Healthcare, Teflex Medical GmbH, Teva GmbH, TopMedMedizintechnik GmbH, Verathon Medical, Vifor Pharma GmbH.

Prof. Meybohm received grants from B. Braun Melsungen and CSL Behring $\mathrm{GmbH}$. Dr. Fischer received grants from the Boehringer Ingelheim Foundation, B. Braun Melsungen and speaker's honoraria from MSD Sharp \& Dohme $\mathrm{GmBH}$, Vifor Pharma GmbH and CSL Behring GmbH.

\section{References}

1 Carson JL, Poses RM, Spence RK, Bonavita G: Severity of anaemia and operative mortality and morbidity. Lancet 1988;i:727-729.

2 Baron DM, Hochrieser H, Posch M, Metnitz B, Rhodes A, Moreno RP, Pearse RM, Metnitz P, for the European Surgical Outcomes Study Group for the Trials Groups of the European Society of Intensive Care Medicine, the European Society of Anaesthesiology: Preoperative anaemia is associated with poor clinical outcome in non-cardiac surgery patients. Br J Anaesth 2014;113: 416-423.

3 Carson JL, Duff A, Poses RM, Berlin JA, Spence RK, Trout R, Noveck H, Strom BL: Effect of anaemia and cardiovascular disease on surgical mortality and morbidity. Lancet 1996;348:1055-1060.

4 Musallam KM, Tamim HM, Richards T, Spahn DR, Rosendaal FR, Habbal A, Khreiss M, Dahdaleh FS, Khavandi K, Sfeir PM, et al: Preoperative anaemia and postoperative outcomes in non-cardiac surgery: a retrospective cohort study. Lancet 2011;378:1396-1407.

5 Marik PE, Corwin HL: Efficacy of red blood cell transfusion in the critically ill: a systematic review of the literature. Crit Care Med 2008;36:2667-2674.

6 Shander A, Goodnough LT: Why an alternative to blood transfusion? Crit Care Clin 2009, 25(2):261-277.

7 Vamvakas EC, Blajchman MA: Transfusion-related mortality: the ongoing risks of allogeneic blood transfusion and the available strategies for their prevention. Blood 2009;113:3406-3417.

8 Rohde JM, Dimcheff DE, Blumberg N, Saint S, Langa KM, Kuhn L, Hickner A, Rogers MA: Health care-associated infection after red blood cell transfusion: a systematic review and meta-analysis. JAMA 2014; 311):1317-1326.

9 Bennett-Guerrero E, Zhao Y, O'Brien SM, Ferguson TB Jr, Peterson ED, Gammie JS, Song HK: Variation in use of blood transfusion in coronary artery bypass graft surgery. JAMA 2010;304:1568-1575.
10 Frank SM, Savage WJ, Rothschild JA, Rivers RJ, Ness PM, Paul SL, Ulatowski JA: Variability in blood and blood component utilization as assessed by an anesthesia information management system. Anesthesiology 2012;117:99-106.

11 Vincent JL, Baron JF, Reinhart K, Gattinoni L, Thijs L, Webb A, Meier-Hellmann A, Nollet G, Peres-Bota D; $\mathrm{ABC}$ (Anemia and Blood Transfusion in Critical Care) Investigators.: Anemia and blood transfusion in critically ill patients. JAMA 2002;288:1499-1507.

12 National Blood Authority Australia: Patient Blood Management Guidelines. www.blood.gov.au/pbmguidelines (last accessed February 12, 2015).

13 Gombotz H, Zacharowski K, Spahn DR: Patient Blood Management: Individual Treatment Concept to Reduce and Avoid Anemia. Stuttgart, Thieme, 2013.

14 World Health Organization: WHO Global Forum for Blood Safety: Patient Blood Management. www.who. int/bloodsafety/events/gfbs_01_pbm/en/ (last accessed February 12, 2015).

15 Shander A, Van Aken H, Colomina MJ, Gombotz H, Hofmann A, Krauspe R, Lasocki S, Richards T, Slappendel R, Spahn DR: Patient blood management in Europe. Br J Anaesth 2012;109:55-68.

16 Farmer SL, Towler SC, Leahy MF, Hofmann A: Drivers for change: Western Australia Patient Blood Management Program (WA PBMP), World Health Assembly (WHA) and Advisory Committee on Blood Safety and Availability (ACBSA). Best Pract Res Clin Anaesthesiol 2013;27:43-58.

17 EU-PBM Patient Blood Management: www.europe pbm.eu (last accessed February 12, 2015).

18 Gesundheitsberichterstattung des Bundes: Consumption of Blood Products in Transfusions (Number in Bags and per 100,000 inhabitants) (in German). www. gbe-bund.de/oowa921-install/servlet/oowa/aw92/dboowasys 921.xwdevkit/xwd_init?gbe.isgbetol/xs_start_neu/ep_aid $=i \nLeftarrow p \_a i d=99295457 \&$ nummer $=687 \& p \_s p r a c h e=D \& p$ indsp=-eppaid=68963649 (last accessed February 12, 2015)
9 Rello J, Lorente C, Bodi M, Diaz E, Ricart M, Kollef $\mathrm{MH}$ : Why do physicians not follow evidence-based guidelines for preventing ventilator-associated pneumonia?: a survey based on the opinions of an international panel of intensivists. Chest 2002;122:656-661.

20 Berwick DM: Disseminating innovations in health care. JAMA 2003;289:1969-1975.

21 Cabana MD, Rand CS, Powe NR, Wu AW, Wilson $\mathrm{MH}$, Abboud PA, Rubin HR: Why don't physicians follow clinical practice guidelines? A framework for improvement. JAMA 1999;282:1458-1465.

22 Francis DO: Bench to trench: how evidence and guidelines shape health care policy and practice. Otolaryngol Head Neck Surg2013;149:356-359.

23 Eddy DM: Evidence-based guidelines: looking back, and looking ahead. Presented at the Evidence-Based Guidelines Affecting Policy, Practice and Stakeholders (E-GAPPS), New York, December 10-11, 2012.

24 Shander A, Puzio T, Javidroozi M: Variability in transfusion practice and effectiveness of strategies to improve it. J Cardiothorac Vasc Anesth 2012;26:541-544.

25 Eddy DM, Adler J, Patterson B, Lucas D, Smith KA, Morris M: Individualized guidelines: the potential for increasing quality and reducing costs. Ann Intern Med 2011;154:627-634.

26 Goodnough LT, Maniatis A, Earnshaw P, Benoni G, Beris P, Bisbe E, Fergusson DA, Gombotz H, Habler O, Monk TG, et al: Detection, evaluation, and management of preoperative anaemia in the elective orthopaedic surgical patient: NATA guidelines. $\mathrm{Br}$ J Anaesth 2011;106:13-22.

27 Goodnough LT, Manaitis A., Earnshaw P, the NATA Consensus Development Working Group: Management of preoperative anaemia in patients undergoing elective surgery. ISBT Sci Ser 2010;5:120-124.

28 Arriaga AF, Bader AM, Wong JM, Lipsitz SR, Berry WR, Ziewacz JE, Hepner DL, Boorman DJ, Pozner CN, Smink DS, et al: Simulation-based trial of surgical-crisis checklists. N Engl J Med 2013;368:246-253. 
29 Raikhel M: Accuracy of noninvasive and invasive point-of-care total blood hemoglobin measurement in an outpatient setting. Postgrad Med 2012;124:250-255.

30 Lasocki S, Krauspe R, von Heymann C, Mezzacasa A, Chainey S, Spahn DR: PREPARE: the prevalence of perioperative anaemia and need for patient blood man agement in elective orthopaedic surgery: a multicentre, observational study. Eur J Anaesthesiol 2015;32:160167.

31 Boral LI, Bernard A, Hjorth T, Davenport D, Zhang D, MacIvor DC: How do I implement a more restrictive transfusion trigger of hemoglobin level of $7 \mathrm{~g} / \mathrm{dL}$ at my hospital? Transfusion 2015; doi: 10.1111/trf.12982.
32 Leahy MF, Roberts H, Mukhtar SA, Farmer S, Tovey J, Jewlachow V, Dixon T, Lau P, Ward M, Vodanovich $\mathrm{M}$, et al: A pragmatic approach to embedding patient blood management in a tertiary hospital. Transfusion 2014;54:1133-1145.

33 Theusinger OM, Kind SL, Seifert B, Borgeat L, Gerber C, Spahn DR: Patient blood management in orthopaedic surgery: a four-year follow-up of transfusion requirements and blood loss from 2008 to 2011 at the Balgrist University Hospital in Zurich, Switzerland. Blood Transfus 2014;12:195-203.
34 Gross I, Seifert B, Hofmann A, Spahn DR: Patient blood management in cardiac surgery results in fewer transfusions and better outcome. Transfusion 2015 doi: $10.1111 /$ trf.12946

35 Camm AJ, Lip GY, De Caterina R, Savelieva I, Atar D, Hohnloser SH, Hindricks G, Kirchhof P; ESC Committee for Practice Guidelines (CPG):: 2012 focused update of the ESC Guidelines for the management of atrial fibrillation: an update of the 2010 ESC Guidelines for the management of atrial fibrillation. Developed with the special contribution of the European Heart Rhythm Association. Eur Heart J 2012;33:2719-2747. Erratum in Eur Heart J 2013;34:790 and Eur Heart J 2013;34 2850-.2851. 